\title{
Age- and Gender-Specific Smoothed Waist Circumference Percentiles for Kuwaiti Adolescents
}

\author{
Robert T. Jackson ${ }^{a}$ Nawal Al-Hamad ${ }^{b}$ Prasanna Prakash $^{b}$ Mona Al-Somaie ${ }^{b}$ \\ ${ }^{a}$ Department of Nutrition and Food Science, University of Maryland, College Park, Md., USA; \\ ${ }^{\mathrm{b}}$ Administration of Food and Nutrition, Kuwait Ministry of Health, Kuwait
}

\author{
Key Words \\ Waist circumference percentiles $\cdot$ Kuwaiti adolescents . \\ Obesity $\cdot$ Heart disease $\cdot$ Diabetes
}

\begin{abstract}
Objective: To ascertain abdominal obesity prevalence (waist circumference, WC) in adolescents and to develop smoothed WC percentile charts for Kuwaiti adolescents for public health use. Subjects and Methods: A cross-sectional study of 4,219 healthy Kuwaiti male and female secondary school students between the ages of 11-19 years was examined. Adolescents were drawn from all geographical regions of the country, as part of the Kuwait Nutrition Surveillance Program (KNSP). The KNSP consists of yearly data collections of variables, including weights, heights, and WCs and several sociodemographic variables. LMS regression was used to develop smoothed WC percentile curves. The final percentile curves presented are the result of smoothing three age-specific curves, termed lambda (L), mu (M), and sigma (S) for each gender. Results: Between 5.9 and $12.8 \%$ of females and $8.0-30.3 \%$ males had WC values $\geq 90$ th percentile. Moreover, the mean WC of males was consistently higher than those of females at each age and the percent of adolescents who exceed the 90th percentile increased with age in males, but not in females. Conclusion: Mean WC was higher in males than in females at every age. In most cases, two to three times greater percentages of males, compared to fe-
\end{abstract}

males, equaled or exceeded the 90th percentile, a value frequently associated with higher cardiovascular risk. These results indicate the urgent need to reduce abdominal obesity, an important indicator of the metabolic syndrome, in Kuwaiti adolescents.

Copyright $\odot 2010$ S. Karger AG, Basel

\section{Introduction}

In the USA, the number of overweight children doubled and the number of overweight adolescents trebled between 1980 and 2000. The prevalence of obese children aged 6-11 years has more than doubled since the 1960s. In a 2002 study, obesity prevalence in adolescents aged 12-17 increased dramatically from 5 to $13 \%$ in boys and from 5 to $9 \%$ in girls between $1966-1970$ and 1988-1991 in the USA [1]. Similar increases in overweight and/or obesity occurred in other countries, i.e. Spain, UK, Australia, etc. In Australian children, for example, obesity tripled between 1985 and 1997 [2]. Recent evidence from a 2008 USA study suggests that while the prevalence is still alarmingly high, the rate of increase in child and adolescent obesity may be slowing [3]. Worldwide, an estimated 22 million children under the age of 5 years have been estimated to be overweight. The problem is global and increasingly extends to the developing world [4]. 
There is considerable evidence that the antecedents of cardiovascular diseases (CVDs, particularly obesity) begin in childhood and continue to progress through adolescence into adulthood [5-8]. Obesity is correlated with atherogenic lesions in adolescents and young adults. Children with greater adiposity and who have higher cholesterol values are more likely to have elevated risk as adults $[8,9]$.

Kuwaiti citizens enjoy a high standard of living that includes free education and medical care, among other amenities. The discovery of oil in the 1950s brought dramatic changes in living standards, including changes in lifestyle, diet and changes to the physical environment. Some of the diet and lifestyle changes have resulted in increases in chronic diseases associated with overweight and obesity, such as heart diseases, diabetes and cancer. A recent study suggests that the metabolic syndrome (MS) is present in $36.2 \%$ of adult males and $36.1 \%$ of adult females [10].

In 2004, Badr [11] found that $44 \%$ of a sample of $\mathrm{Ku}-$ waiti high school adolescents were overweight or obese. In 2003 in a large household survey of 7,609 apparently healthy Kuwaitis aged 15 years and older, Olusi et al. [12] found that 23.5\% of the sample was obese. In 2009, El Bayoumy et al. [13] studied total obesity in a sample of 5,402 adolescents by calculating BMI and found that $29.3 \%$ of boys and $32.1 \%$ of girls were overweight and $14.9 \%$ of boys and $14.2 \%$ of girls were obese.

There is a paucity of studies of obesity in Kuwait, particularly studies that have examined abdominal obesity. The World Health Organization raised concern about the distribution of body fat, since excess fat in the abdominal area both in children and adolescents [5-9] and adults [14] seems to be more highly correlated with hyperlipidemia, CHD risk factors, type 2 diabetes, and other comorbidities than is overall obesity $[10,14,15]$. Abdominal obesity is one of the indicators of the MS, a cluster of indicators believed to increase the risk of CVD and type 2 diabetes mellitus [10, 16-18].

Although waist circumference (WC) is an accepted measure of abdominal obesity and has been shown to be highly correlated with diabetes, even in some adolescents $[5,7,17]$, there is some disagreement about what cutoff levels should be used for their measurement among various ethnic groups. Two prominent groups, the National Cholesterol Education Program Adult Treatment Panel III (NCEP ATPIII) of the USA and the International Diabetes Federation (IDF), use WC to define the MS. However, in the IDF definition large WC (along with two additional abnormal indicators) is critical to establish the definition of MS. NCEP requires that any three of the same five indicators be aberrant. Both organizations agree that WC is an important indicator for CVD and type 2 diabetes mellitus risk and currently recommend different WC cutoff points that depend upon the ethnicity of study subjects.

No studies have been done to ascertain an appropriate WC cutoff for Kuwaitis, or other Gulf Arabs. Thus, there are no agreed upon WC cutoffs for adult or adolescent Arabs. We use the LMS regression methods, as suggested by the International Obesity Task Force, to develop the first age- and gender-specific WC cutoffs for Kuwaiti adolescents [19]. This is important since available epidemiological data reveal that chronic disease, especially diabetes mellitus, is a leading cause of morbidity and mortality in Kuwaiti adults [10] and abdominal obesity is an antecedent that begins even in childhood and adolescence [5-9]. In children, body fatness changes with maturation during the child and adolescent years. In addition, during maturation, boys and girls have different patterns of body fatness. These differences necessitate different anthropometric cutoffs by age and gender.

The development of age- and gender-specific WC percentiles is necessary both for population and clinical screening purposes, as their use can draw attention of the public health and clinical communities to serious excesses (e.g. values $\geq 90$ th percentile) in central obesity.

This research sought to ascertain the prevalence of abdominal obesity (measured by WC) in adolescent boys and girls. We also sought to develop new WC percentile tables and charts for Kuwaiti adolescents for use in this age cohort.

\section{Subjects and Methods}

Kuwait is oil rich and is located at $30.27^{\circ} \mathrm{N}$ and $48.46^{\circ} \mathrm{E}$. Iraq borders Kuwait to the north and west, The Kingdom of Saudi Arabia is to the south, and the Arabian Gulf forms the eastern border. The total population numbers 2,691,158; however, 1,291,354 of that number (about one-half) are non-nationals [20]. Kuwait's infant mortality rate is 8.9 , and the life expectancy at birth is 77.7 years. The 2008 per capita income was USD 57,400, making it one of the wealthiest countries in the world [20].

We studied 4,219 healthy Kuwaiti adolescent boys and girls who were attending various secondary schools throughout the country. The sample consisted of 11.0- to 18.9-year-old students, was broadly representative of students between the ages of 11.0 and 18.9 years of age, and was drawn from all 6 geographical regions of the country, as part of the 2006 Kuwait Nutrition Surveillance Program (KNSP). The study protocol was reviewed and approved by the Kuwait Ministries of Health and Education, and the study was conducted after obtaining written consent from the 
Table 1. Mean WC and percent of Kuwaiti adolescents with circumferences $\geq 90$ th percentile by age and gender

\begin{tabular}{|c|c|c|c|c|c|c|}
\hline \multirow{2}{*}{$\begin{array}{l}\text { Age } \\
\text { years }\end{array}$} & \multicolumn{3}{|c|}{ Girls } & \multicolumn{3}{|c|}{ Boys } \\
\hline & $\mathrm{n}$ & $\mathrm{WC}, \mathrm{cm}$ & $\geq 90$ th percentile, $\%$ & $\mathrm{n}$ & $\mathrm{WC}, \mathrm{cm}$ & $\geq 90$ th percentile, $\%$ \\
\hline $11-11.9$ & 214 & $69.9 \pm 11.5$ & 10.3 & 179 & $72.0 \pm 12.8$ & 8.9 \\
\hline $12-12.9$ & 255 & $71.6 \pm 11.0$ & 5.9 & 232 & $74.5 \pm 13.6$ & 14.7 \\
\hline $13-13.9$ & 263 & $72.5 \pm 10.9$ & 6.1 & 279 & $75.7 \pm 13.9$ & 17.5 \\
\hline $14-14.9$ & 320 & $75.3 \pm 11.7$ & 12.8 & 365 & $78.8 \pm 15.3$ & 24.4 \\
\hline $15-15.9$ & 282 & $73.7 \pm 12.0$ & 9.9 & 283 & $82.2 \pm 16.1$ & 30.0 \\
\hline $16-16.9$ & 272 & $73.6 \pm 11.6$ & 8.8 & 363 & $82.3 \pm 16.1$ & 27.8 \\
\hline $17-17.9$ & 291 & $73.0 \pm 12.6$ & 10.7 & 317 & $83.6 \pm 15.9$ & 30.3 \\
\hline $18-18.9$ & 165 & $74.0 \pm 12.7$ & 10.3 & 139 & $81.8 \pm 15.7$ & 25.2 \\
\hline Total & 2,062 & & 9.4 & 2,157 & & 18.9 \\
\hline
\end{tabular}

parents of the school children. The KNSP has been described in detail elsewhere $[15,21]$, but briefly consists of yearly data collections of hemoglobin concentrations, weights, heights, cholesterol values and several sociodemographic variables. The Kuwait $\mathrm{Nu}-$ trition Surveillance system is designed to continuously monitor the nutritional health status of different Kuwaiti population groups and to provide data as an instrument of policy formulation and health intervention evaluation for health workers and decision makers. The KNSP data are collected on Kuwaiti citizens.

Identifying background information including age, grade, and locality (governorate) of residence were collected onto structured questionnaires. Trained and experienced field researchers measured weights (to nearest $0.1 \mathrm{~kg}$ ) and heights (to nearest 0.1 $\mathrm{cm}$ ), using World Health Organization protocols.

WCs were measured at the midpoint between the top of the iliac crest and lower part of the last rib. The 90th percentile of WC is a cutoff value that is commonly associated with increased risk for comorbidities in adults [18]. It is a value that is used to represent risk in various populations for different anthropometric variables. So we used the 90 th percentile as putative evidence of increased risk for these adolescents.

Descriptive (means and frequencies) and inferential statistics were calculated for various background variables. A $\mathrm{p}$ value of $\leq 0.05$ was taken to be significant.

In order to develop smoothed WC percentile curves and tables for Kuwaiti adolescents, we used the LMS regression technique of Cole and Green [19] recommended by the International Obesity Task Force and calculated using the software program Chartmaker Pro (Institute of Child Health, London). In this method, the percentile value for each of the standardized WC thresholds was calculated and smoothed by using LMS regression [19]. The LMS method involves summarizing percentiles at each age on the basis of Box-Cox power transformations, which are used to normalize the data. The final percentile curves are the result of smoothing three age-specific curves, termed lambda (L), mu (M), and sigma (S). The L, M, S curves describe the skewness, median, and coefficient of variation of the distribution of WCs at each age [19]. Statistical analyses were performed with SPSS (version 15.0, Chicago, Ill., USA).

\section{Results}

This study was conducted on 4,219 healthy Kuwaiti adolescent boys $(n=2,157)$ and girls $(n=2,062)$ who were enrolled in various secondary schools throughout $\mathrm{Ku}-$ wait.

The mean age of the boys was 15.0 ( \pm 2.0 year) years, compared with 14.9 ( \pm 2.2 year) years for the girls. The mean weight and height of the girls were $57.1 \mathrm{~kg}$ and $1.55 \mathrm{~m}$ and those of the boys $64.9 \mathrm{~kg}$ and $1.63 \mathrm{~m}$, respectively.

Abdominal obesity (WC) was correlated with students' age and grade level. Mean WC of adolescent boys and girls by age are given in table 1 . It also shows the percent of boys and girls who have WC $\geq 90$ th percentile of the distribution, a value commonly associated with increased risk for comorbidities in adults $[18,19]$. The mean WC of both boys and girls tended to increase with age. The mean WC of boys was consistently higher than those of the girls at each age. From age 12.0 years onward in our sample, there were greater percentages of boys than girls with WC $\geq 90$ th percentile. At some ages (e.g. 15.0-15.9 and 17.0-17.9 years), the percent of boys above the 90th percentile exceeded $30 \%$. Overall, the percent of adolescents who exceed the 90th percentile increased with age in boys, but not in girls.

Age- and gender-specific smoothed WC percentiles for boys and girls by age are given in table 2 . Percentile values for boys are consistently higher than those for girls at each percentile level and at each age; that is, within each age level (from 11 to 18 years) boys had higher WC percentiles than girls. Boys also displayed higher smoothed percentiles than girls at each percentile cutoff value (from the 5 th through 95th percentile), as shown in table 2 . 
1

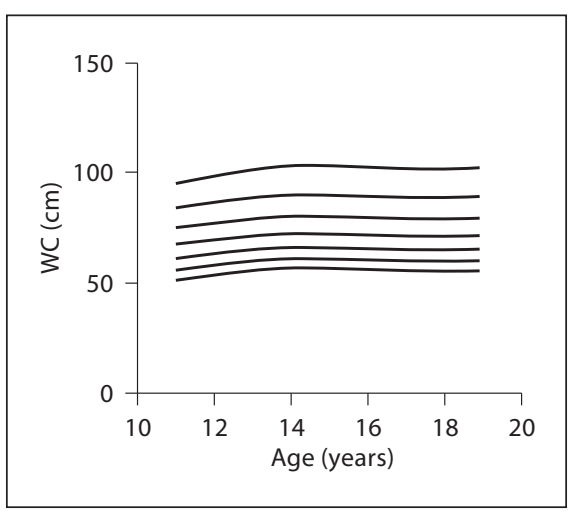

2

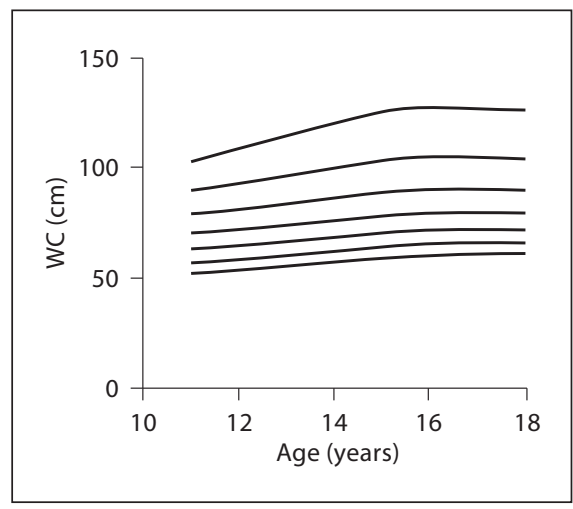

Fig. 1. Smoothed WC curves for Kuwaiti adolescent girls by age.

Fig. 2. Smoothed WC curves for Kuwaiti adolescent boys by age.
The smoothed WC percentiles for 11.0- through 18.9-year-old Kuwaiti adolescents are shown in figures 1 and 2 , respectively. The percentile chart of WC values for boys was higher and steeper than that for girls.

\section{Discussion}

There is growing evidence to suggest that obesity is highly correlated with the subsequent development of comorbidities [17, 22-24] and that children and adolescents who are obese and who have larger WC are at higher risk for the development of later chronic disease than are those without obesity or who have lower or normal WCs [5-9]. There is also evidence that abdominal fat differs among different ethnic groups, making assessments based on a single international waist cutoff inappropriate for all groups [18]. Thus, it is important for screening and assessment purposes to develop and use WC percentiles developed within various ethnic groups. This is the first report of smoothed WC percentile tables and curves for Kuwaiti adolescents 11-19 years of age.

The mean WCs were higher in boys than in girls at every age. These results were similar to those found for Canadian [25] and American adolescents [26] where boys also had greater WCs at every age than girls. Moreover, for most ages, the percent of boys who were at or exceeded the 90th percentile was consistently greater than that of girls. In most cases, two to three times greater percentages of boys, compared to girls, equaled or exceeded the 90th percentile value.

Compared to published WC measurements in adolescents of other countries (e.g. in Canada, America, and Australia), our results show that Kuwaiti adolescents have among the highest percentages of abdominal adiposity 
reported thus far. For example, their values exceeded the WCs reported for Australian [2] and Canadian adolescents [25]. Kuwaiti adolescent boys had values that exceeded those reported in American adolescent boys at every age studied at the 90 th percentile and in four age categories of the 50th percentile (11-14, 15-16 years of age). It was only at age $14-15$ years that American and Kuwaiti mean WCs were the same. Interestingly, Kuwaiti girls had consistently lower values than their American counterparts at every age, both at the 50th and the 90 th percentiles [26]. The percent of boys who exceeded the 90th percentile was twice that of the girls, suggesting much greater cardiovascular risk and need for intervention in the boys.

Kuwaiti girls exceeded the estimated combined percentile regression values calculated by Fernández et al. [26] for all American children and adolescents (which included European-Americans, African-Americans and Mexican-Americans) from age 11.0 through age 14.9 years. Kuwaiti boys also exceeded the combined American values at each age between 11.0 and 17.9 years of age. Only at age 18.0-18.9 did values in American boys exceed the values in Kuwaiti boys. Similar findings have been reported when total obesity was studied among Kuwaiti adolescents. In a 2008 report, Al-Isa and Thalib [27] found that Kuwaiti children were heavier (had larger BMI averages) than American children of similar ages (10-14 years).

According to the NCEP definition of the MS, a value of $88 \mathrm{~cm}$ is used as a cutoff for risk of developing obesity- related conditions for adult women [28]. Kuwaiti adolescent girls exceeded this value at each age $\geq 14$ years. Only the 11- to 13-year-old girls had a WC lower than that value. For adult men, a WC of $102 \mathrm{~cm}$ is suggestive of the MS. Again, only the 11.0- to 13.9-year-olds were below this value. All those $\geq 14.0$ years of age exceeded this value. In boys, the trend for the $\mathrm{WC}$ values was to increase from 14.0 years up through 17.9 years of age. Since the incidence of CHD is higher in adult males than females, the early development of abdominal obesity seen in this study, starting at age 14 years in both boys and girls, is of concern.

Prior to this study, no WC references existed for $\mathrm{Ku}-$ wait or other Gulf Arab countries. However, since many Kuwaitis have the same ancestry as other Gulf Arabs, particularly those in Saudi Arabia, these smoothed percentiles may also be helpful as a first step in exploring abdominal obesity in other Gulf countries [27].

\section{Conclusions}

Mean WCs were higher in males than in females at every age. In most cases, two to three times greater percentages of males, compared to females, equaled or exceeded the 90th percentile, a value frequently associated with higher cardiovascular risk. These results indicate the urgent need to reduce abdominal obesity, an important indicator of the MS, in Kuwaiti adolescents.

\section{References}

1 Ogden CL, Flegal KM, Carroll MD, Johnson CL: Prevalence and trends in overweight among US children and adolescents, 19992000. JAMA 2002;288:1728-1732.

2 Booth ML, Chey T, Wake M, Norton K, Hesketh K, Dollman J, Robertson I: Change in the prevalence of overweight and obesity among young Australians, 1969-1997. Am J Clin Nutr 2003;77:29-36.

3 Ogden CL, Carroll MD, Flegal KM: High body mass index for age among US children and adolescents, 2003-2006. JAMA 2008; 299:2401-2405.

4 Wang Y, Lobstein T: Worldwide trends in childhood overweight and obesity. Intl J Pediatr Obes 2006;1:11-25.
Brambilla P, Bedogni G, Moreno LA, Goran MI, Gutin B, Fox KR, Peters DM, Barbeau P, De Simone M, Pietrobelli A: Cross validation of anthropometry against magnetic resonance imaging for the assessment of visceral and subcutaneous adipose tissue in children. Int J Obes (Lond) 2006;30:23-30.

6 Bibbins-Domingo K, Coxson P, Pletcher MJ, Lightwood J, Goldman L: Adolescent overweight and future adult coronary heart disease. N Engl J Med 2007;357:2371-2379.

7 Lawlor DA, Leon DA: Association of body mass index and obesity in early childhood with risk of coronary heart disease and stroke in middle age: findings from the $\mathrm{Ab}$ erdeen children of the 1950s prospective cohort study. Circulation 2005;111:1891-1896.

$\checkmark 8$ Cruz ML, Goran MI: The metabolic syndrome in children and adolescents. Curr Diab Rep 2004;4:53-62.
Ram Weiss R, Dziura J, Burgert TS, Tamborlane WV, Taksali SE, CW, Allen K, Lopes M, Savoye M, Morrison J, Sherwin RS, Caprio S: Obesity and the metabolic syndrome in children and adolescents. N Engl J Med 2004; 350:2362-2374.

10 Al Rashdan IR, Nesef YA: Prevalence of overweight, obesity and metabolic syndrome among adult Kuwaitis: results from community-based national survey. Angiology 2010; 61:42-48.

11 Badr Hel-S: Obesity and personality types of high school boys in Kuwait. J Egypt Public Health Assoc 2004;79:449-460.

12 Olusi SO, Al-Awadi AM, Abraham M: Baseline population survey data on the prevalence of risk factors for coronary artery disease among Kuwaitis aged 15 years and older. Ann Saudi Med 2003;23:162-166. 
13 El-Bayoumy I, Shady I, Lofty H: Prevalence of obesity among adolescents (10-14 years) in Kuwait. Asia Pac J Public Health 2009;21: 153-159.

-14 Katzmarzyk PT, Perusse L, Malina RM, Bergeron J, Despres JP, Brouchard C: Stability of indicators of the metabolic syndrome from childhood to adolescence to young adulthood: the Quebec Family Study. J Clin Epidemiol 2001;54:190-195.

- 15 Jackson RT, Al-Mousa Z, Al-Raqua M, Prakash P, Muhanna AN: Multiple coronary risk factors in healthy older Kuwaiti males. Eur J Clin Nutr 2002;56:709-714.

$\checkmark 16$ Musiager AO: Diet and prevention of coronary heart disease in the Arab Middle East countries. Med Princ Pract 2002;11:9-16.

$\checkmark 17$ Pouliot MC, Despres JP, Lemieuz S, Moorjani S, Bouchard C, Tremblay A, Nadeau A, Lupien PJ: Waist circumference and abdominal sagittal diameter: best simple anthropometric indexes of abdominal visceral adipose tissue accumulation and related cardiovascular risk in men and women. Am J Cardiol 1994;73:460-468.
18 Maffeis C, Pietrobelli A, Grezzani A, Provera S, Tato L: Waist circumference and cardiovascular risk factors in pubertal children. Obes Res 2001;9:179-187.

19 Cole TJ, Green PJ: Smoothing reference centile curves: the LMS method and penalized likelihood. Stat Med 1992;11:1305-1319.

20 World Fact Book https://www.cia.gov/library/publications/the-world-factbook/ geos/KU.html; retrieved 2009.

21 Jackson RT, Rashed M, Al-Hamad N, Hwalla $\mathrm{N}$, Al-Somaie M: Comparison of BMI-forage in adolescent girls in 3 countries of the Eastern Mediterranean Region. East Mediterr Health J 2007;13:430-440.

22 National Institutes of Health: Clinical Guidelines for the Identification, Evaluation, and Treatment of Overweight and Obesity in Adults. Bethesda, National Institutes of Health, 1998.

23 Lee JM, Davis MM, Woolford SJ, Gurney JG: Waist circumference percentile thresholds for identifying adolescents with insulin resistance in clinical practice. Pediatr Diabetes 2009; 10:336-342.
24 Koster A, Leitzmann MF, Schatzkin A, Mouw T, Adams KF, van Eijk JT, Hollenbeck AR, Harris TB: Waist circumference and mortality. Am J Epidemiol 2008;167:14651475 .

25 Katzmarzyk PT: Waist circumference percentiles for Canadian youth 11-18 y of age. Eur J Clin Nutr 2004;58:1011-1015

26 Fernández JR, Redden DT, Pietrobelli A, Allison DB: Waist circumference percentiles in nationally representative samples of African-American, European-American, and Mexican-American children and adolescents. J Pediatr 2004;145:439-444.

27 Al-Isa AN, Thalib L: Body mass index of Kuwaiti adolescents aged 10-14 years: reference percentiles and curves. East Mediterr Health J 2008; 14:333-343.

28 McDowell MA, Fryar CD, Hirsch R, Ogden CL: Anthropometric reference data for children and adults: US population, 1999-2002. Advance data from vital and health statistics; No. 361. Hyattsville, National Center for Health Statistics, 2005. 
